\title{
Sustainable Thermosets Obtained by Copolymerization of Humins with Triglycidyl Ether of Phloroglucinol
}

\author{
Roxana Dinu ${ }^{1} \&$ Alice Mija ${ }^{1}$ \\ ${ }^{1}$ Université Côte d'Azur, Institut de Chimie de Nice, UMR CNRS, France \\ Correspondence: Alice Mija, Université Côte d'Azur, Institut de Chimie de Nice, UMR CNRS 7272, 06108 Nice \\ Cedex 02, France. Tel: +33-4-8915-0174. E-mail: Alice.MIJA@univ-cotedazur.fr
}

Received: February 22, 2020

Accepted: March 26, 2020

Online Published: April 1, 2020

doi:10.5539/jmsr.v9n1p1

URL: https://doi.org/10.5539/jmsr.v9n2p1

\begin{abstract}
The environmental pollution is growing continuously - causing a worldwide problem. Production and use of petroleum-based materials but also huge quantities of industrial wastes are important factors that affect the wellbeing of the environment. New scientific researches place great emphasis on waste valorization, and also on developing new environmentally friendly bio-based materials. In this work we focus on the valorization of humins, a biorefinery side product, by its copolymerization with a bio-based triepoxide. In this manner we produce materials with a very high bio-based carbon content $(B C C) \approx 94 \%$. The physico-chemical and mechanical properties of the cured bio-based resins were investigated using different technics as TGA, DMA, Shore hardness test, water absorption and solvents resistance. It was revealed that the obtained materials present very good mechanical properties with values of $E^{\prime}$ in glassy region $\approx 3.7-5 \mathrm{GPa}$. The $\tan \delta$ - maxima of the three huminsbased resins are ranging from 122 to $154^{\circ} \mathrm{C}$. The thermosets' hardness values $\approx 82-85 \mathrm{SD}$ confirm the stiffness of these materials.
\end{abstract}

Keywords: Humins, Bio-Based Epoxy Monomer, Sustainable Thermosets, Thermomechanical Properties

\section{Introduction}

Plastics or synthetic organic polymers are extremely highly used materials, their production and employment increasing significantly and exceeding almost all others human-developed materials. Most plastics materials use in their production fossil derivatives as raw materials, and commonly these used plastics are non-biodegradable, which leads to ecological disaster by the huge quantities of waste generation. The use of fossil derivatives and the production of non-biodegradable waste are some of the biggest problematics of the 21 st century, namely the pollution of the environment (Brostow \& Hagg Lobland, 2017; European commission, 2011). According to studies, in 2015 were generated $6300 \mathrm{Mt}$ of plastic waste, of which $9 \%$ were recycled, $12 \%$ incinerated and $79 \%$ were deposited in landfills or in nature (Geyer, Jambeck, \& Law, 2017; Ritchie \& Roser, 2018). In order to combat these major problems, intense research has begun on the development of materials from bio-resources and industrial waste. This work proposes to develop new green thermoset materials based on biorefineries side-products like the humins and a bio-based monomer as triglycidyl ether of phloroglucinol (TGPh).

The epoxy resins represent one of the most important class of thermosetting materials that are used in many sectors of applications, such as automobiles and transports, constructions and civil constructions, electrical and electronic energy, packaging, etc. (Bobade, Paluvai, Mohanty, \& Nayak, 2016; Ménard et al., 2015). The epoxy group can undergo a myriad of chemical reactions by following a wide variety of mechanisms to produce materials with a wide range of properties. In this work we propose the study of a green epoxy monomer in order to develop sustainable thermoset materials: i.e. the triglycidyl ether of phloroglucinol. Phlorotannins are polyphenol compounds found in marine brown algae or in the bark of fruit. These compounds are present in non-vascular plant tannins, being composed of phloroglucinol (1,3,5-trihydroxybenzene) units with different degrees of polymerization (Arbenz \& Avérous, 2015; Y. Li et al., 2017). Due to the abundance in the aquatic environment of this polyphenols as well as its bioactivity and its beneficial effects on health (antioxidant, anti-allergic, anticarcinogenic, anti-inflammatory activity, etc), researches on their potential uses in the medical field has increased considerably (Kirke, Smyth, Rai, Kenny, \& Stengel, 2017; Ornaghi-Junior, Zattera, \& Amico, 2014; Park et al., 2019). Also, intensive researches are being carried out on the use of phloroglucinol as a renewable resource in the development of various monomers in order to limit the environmental impact of the production of polymers. In 
order to develop fully bio-based flame-retardant epoxy resins, Menard et al. (Ménard et al., 2015) functionalized the phloroglucinol by glycidylation and/or phosphorylation, the obtained monomers being cross-linked with a biobased diamine. In the first step, these bio-based flame-retardant epoxy resins were analysed in order to identify the influence of the chemical structure of monomers and hardeners on the thermal and fireproof properties of the thermosets. After, the obtained resins have been compared to a conventional DGEBA-IPDA reference system to determine their overall thermal and fire behavior. In another study, $\mathrm{Ng}$ el al. (Ng, Bonnet, David, \& Caillol, 2017) developed novel food contact low-toxic epoxy coatings based on bio-based epoxy compounds as epoxidized cardanol, diglycidyl ether of vanillin or triglycidyl ether of phloroglucinol and dicyandiamide. This green monomer was involved also in the development of other categories of materials such as porous carbonaceous materials used as adsorbents in chemical and environmental fields (Peer, Qajar, Rajagopalan, \& Foley, 2014; Tripathi et al., 2014) or electrode materials for high-performance supercapacitors (Gao et al., 2018; Huang et al., 2017). Due to its versatility, but also its abundance in nature, phloroglucinol represents a potential alternative to fossil compounds in the materials industry.

Humanity evolution and the standard of living has led to a significant increase in the consumption of chemicals, energy and fuels, these compounds being generally obtained from non-renewable and exhaustible fossil raw materials. A valuable and abundant alternative sustainable feedstock for the conversion into chemical-platform molecules is represented by lignocellulosic biomass. The largest constituents of lignocellulose are the carbohydrates such as cellulose and hemicellulose, representing about $70-80 \mathrm{wt} . \%$ of this biomass (Isikgor \& Becer, 2015). Conversion of these carbohydrates into valuable chemical-platform molecules as 5-hydroxymethyl furfural (HMF), furfural (FF) and levulinic acid (LA), taking place under acid-catalyzed hydrolysis, represent an important part of the biorefinery concept. Besides the production of valuable chemical building blocks, the dehydration of sugar generates also the formation of dark-colored viscous by-product (Patil \& Lund, 2011). This polymeric side-product called humins, is a complex and heterogenous product, lacking a well-defined molecular structure. In order to streamline the biomass conversion through biorefineries processing, a good knowledge and understanding of physico-chemical properties and potential of application of the humins by-product are required. To elucidate the molecular structure and morphology of this by-product, Van Zandvoort et al. (Van Zandvoort et al., 2013) studied different laboratory humins products as a function of feedstock and processing parameters. The reaction conditions were established with the purpose of an ideal simulation of the typical biorefinery operations. Following the investigation of the laboratory humins developed by dehydration of D-glucose, Hoang et al. (Hoang, Eck, Gardeniers, Lefferts, \& Seshan, 2015) observed that this by-product has a variable furan structure that contains a variety of functional groups such as alcohol, acid, ketone and aldehyde. Based on the studies so far, humins are carbon-rich agglomerate particles, composed of approximately $50-65 \mathrm{wt} . \% \mathrm{C}, 29-46 \% \mathrm{wt} . \% \mathrm{O}$, and 4-5.5 wt.\% $\mathrm{H}$, depending on the process parameters and feedstock (Constant, Lancefield, Weckhuysen, \& Bruijnincx, 2017; Filiciotto, Balu, Van der Waal, \& Luque, 2018; Hu, Lievens, Larcher, \& Li, 2011). Until recently, due to the variation of the degree of branching and the molecular mass of humins oligomers depending on the production process, the industrial uses of this by-product were limited only to the conversion of energy and power by gasification or combustion ( Hoang, Lefferts, \& Seshan, 2013; Muralidhara, Tosi, et al., 2018). Furthermore, the complex structure and the abundance of different functional groups convert the humins into a promising renewable material for new innovative end-products such as absorbents for wastewater treatment, insulation materials, support for solid catalysts or furanic resins and composites for different industrial sector applications (Kang et al., 2018; Patent No. WO2018/062995 A1, 2018; Patent No. WO 2017/074183 A8, 2017; Tosi et al., 2018). In our previous studies, (Dinu \& Mija, 2019; Montané, Dinu, \& Mija, 2019; Pin et al., 2014) the industrial humins were intensely studied and converted into valuable bio-materials. For example, industrial humins were copolymerized with aliphatic diglycidyl ethers obtaining different thermoset resins (Dinu \& Mija, 2019). By tailoring both the composition and the process parameters of the resins, their physico-chemical and mechanical properties have been modulated, thus obtaining a variety of materials, from elastic to rigid for a large industrial applications area. In another study, Pin et al. (Pin et al., 2014) developed fully bio-based furanic resins by combining the industrial humins with polyfurfuryl alcohol (PFA). Thereafter, PFA/humins thermoset resins were used as matrices in the development of composites, where cellulose acted as reinforcing materials.

Given that the need to replace fossil materials with renewable ones is increasing, the purpose of this study is the development of sustainable materials. The copolymerization study of the humins with triglycidyl ether of phloroglucinol, initiated and/or accelerated by various compounds and the reactivities of the obtained systems were already explained in detail in our previous work (Cantarutti, Dinu, \& Mija, 2019). The physico-chemical and mechanical properties of the humins-based thermoset resins were analyzed in this study using different techniques and methods such as differential scanning calorimetry (DSC), thermogravimetric analysis (TGA), dynamic 
mechanical analysis (DMA), Shore hardness test, water absorption or chemical resistance test in order to determine their potential uses at industrial level.

\section{Materials and Methods}

\subsection{Materials}

One of the main compounds used in the development of the thermoset resins presented in this study is represented by the industrial polymeric black by-product called Humins produced and supplied by Avantium Chemicals at their Pilot Plant in Geleen, The Netherlands. In order to obtain sustainable thermosets, the humins were copolymerized with triglycidyl ether of phloroglucinol (TGPh) with $7.8 \mathrm{meq} / \mathrm{g}$ epoxy content and a repeating unit number (n) between 0.5-1.2, supplied by Specific Polymers (Castries-France). N, N-Dimethylbenzylamine (BDMA) and 2,4,6-Tris(dimethylaminomethyl)phenol (DMP-30) purchased from Sigma-Aldrich were used as received to initiate and accelerate the copolymerization and crosslinking between the two bio-compounds.

\subsection{Samples Preparation}

To design and to develop sustainable thermosets the proper amount of humins (55 wt.\%) was weighted and heated on a heating plate to reduce its viscosity. The necessary amount of epoxy comonomer (40 wt.\% TGPh) was added and mechanically mixed under temperature with the preheated humins. To obtain the optimal parameters for the copolymerization different amounts of catalyst (BDMA) / accelerator (DMP-30) were analyzed individually or in combination of both. The thermodynamic parameters (time and temperature) of curing but also the reactivity of all the mixtures were analyzed in order to select the optimal formulations for the development of the materials. After the reactivity study, three formulations were selected. The mixture of humins with TGPh was combined with $5 \mathrm{wt} . \%$ BDMA or $5 \mathrm{wt} . \%$ DMP-30 but also with both $(2.5 / 2.5 \mathrm{wt} . \%)$, poured into silicone molds and cured in oven. The materials were crosslinked for $2 \mathrm{~h}$ at $80{ }^{\circ} \mathrm{C}$ and after another $2 \mathrm{~h}$ at $150{ }^{\circ} \mathrm{C}$. Thereafter, the materials were post-cured at $180^{\circ} \mathrm{C}$ for $1 \mathrm{~h}$. In order to facilitate the identification of the different formulations, the compounds were noted with the following acronyms: "Hu" for humins, "Ep" for TGPh epoxide, "C" for BDMA catalyst and "A" for DMP-30 accelerator. According to these abbreviations, formulation "HuEpC" correspond to the resin with 55 wt.\% humins/ 40 wt.\% TGPh / 5 wt.\% BDMA, "HuEpA" for the system with 55 wt.\% humins/ 40 wt.\% TGPh/ 5 wt.\% DMP-30 and "HuEpAC" for the formulation with 55 wt. $\%$ humins/ 40 wt. $\%$ TGPh / 2.5 wt. \% BDMA / 2.5 wt.\% DMP-30. The physico-chemical and mechanical properties of the three selected formulations were analyzed and compared.

\subsection{Differential Scanning Calorimetry (DSC)}

The thermal aspects of copolymerization were analyzed by differential scanning calorimetry, performed with a Mettler-Toledo DSC 3 apparatus equipped with STARe Software. The crosslinking reactions between humins and TGPh were directly performed in $40 \mu 1$ aluminum pans. Samples of 5-8 mg were reacted under non-isothermal conditions between $25-230^{\circ} \mathrm{C}$ at a heating rate of $10^{\circ} \mathrm{C} \cdot \mathrm{min}^{-1}$. The DSC studies have been used also to study the completion of chemical conversions or the glass transitions of the thermoset samples prepared in oven. For this, samples of 8-12 mg of cured materials were introduced into $40 \mu \mathrm{l} \mathrm{Al}$ crucibles, and studied over a temperature range from $-50^{\circ} \mathrm{C}$ to $150{ }^{\circ} \mathrm{C}$. The tests were performed at a heating rate of $10^{\circ} \mathrm{C} \cdot \mathrm{min}^{-1}$.

\subsection{Dynamic Mechanical Analysis (DMA)}

The dynamic mechanical measurements were conducted in a Mettler Toledo DMA 1 apparatus equipped with a three-points bending assembly. The humins-based thermosets were prepared in rectangular shapes of established dimensions (48 length $\mathrm{x} 8$ width $\mathrm{x} 4$ thickness $\mathrm{mm}^{3}$ ). The DMA tests were performed in the temperature-scanning mode from $-70{ }^{\circ} \mathrm{C}$ to $225^{\circ} \mathrm{C}$, with a constant displacement amplitude of $20 \mu \mathrm{m}$ and a frequency of $1.0 \mathrm{~Hz}$, at a heating rate of $3{ }^{\circ} \mathrm{C} \cdot \mathrm{min}^{-1}$ under nitrogen atmosphere. By this method, the storage (E') and loss (E”) Young modules but also the damping factor ( $\tan \delta=E^{\prime \prime} / E^{\prime}$ ) of the thermosets were determined. According to ASTM E1640-13 (ASTM-E1640, 2013) and ASTM D7028-07 (ASTM-D7028, 2008), three different values of glass transition $\left(T_{g}\right)$ were determined from DMA measurements such as $T_{g \text {-onset }}$ related to the $E$ ' drop, $T_{g \text {-loss }}$ defined as maximum temperature of $E$ " and $T_{\text {g-peak }}$ corresponding to the maximum temperature of the damping factor $\tan \delta$. The DMA analysis was also used to obtain collections of frequency data as a function of temperature in order to develop the master curves of humins-based resins and to study the effect of frequency on changes caused by temperature on materials. The measurements were performed in the frequency range $10 \mathrm{~Hz}$ to $0.1 \mathrm{~Hz}$ at a logarithmic increment of 10 steps/decade, under isothermal conditions at different temperatures between $-25{ }^{\circ} \mathrm{C}$ to $250^{\circ} \mathrm{C}$. The maximum force amplitude was $0.1 \mathrm{~N}$ and the displacement amplitude was $20 \mu \mathrm{m}$. 


\subsection{Density of the Thermoset Resins}

The density of the final resins was determined experimentally using the ISO 9427 standard. For five rectangular samples $\left(50 \times 8 \times 4 \mathrm{~mm}^{3}\right)$ of each formulation the volume was calculated, and the mass was determinate by weighing with a ML3002T Mettler-Toledo precision balance. The density of the samples was calculated as the ratio of the mass to volume.

\subsection{Shore Hardness Test}

A Zwick Roell 3116 Hardness Tester was used to determine the hardness of the humins-based resins, in accordance with ISO 7619-1, ASTM D2240 and ISO 868. The Shore D hardness device was pressed smoothly against the samples with a load force of $50 \mathrm{~N} \pm 0.5 \mathrm{~N}$. The samples hardness value was read after the firm contact between the presser foot and the tested materials.

\subsection{Thermogravimetric Analysis (TGA)}

To determine the thermal stability of the materials a TGA 2 Mettler-Toledo apparatus was used. The thermal behavior of samples in oxidative atmosphere was analyzed in the temperature range from $25^{\circ} \mathrm{C}$ to $1000{ }^{\circ} \mathrm{C}$, at a heating rate of $10^{\circ} \mathrm{C} \cdot \mathrm{min}^{-1}$ and an air flow of $150 \mathrm{~mL} \cdot \mathrm{min}^{-1}$. In order to determine the influence of the heating rate on the thermal stability, the resins were analyzed between $25-1000{ }^{\circ} \mathrm{C}$, in nitrogen flow $\left(150 \mathrm{~mL} \cdot \mathrm{min}^{-1}\right)$, varying the heating rates from $5{ }^{\circ} \mathrm{C} \cdot \mathrm{min}^{-1}$ to $40^{\circ} \mathrm{C} \cdot \mathrm{min}^{-1}$. For both methods of analysis, samples with weight between 9 $12 \mathrm{mg}$ were tested in $70 \mu \mathrm{l}$ aluminum pans.

\subsection{Water Absorption}

Water absorption at $25^{\circ} \mathrm{C}$ of humins-based resins was determined according to ASTM D570 standard test method (ASTM-D570, 1998). Five rectangular $\left(50 \times 8 \times 4 \mathrm{~mm}^{3}\right)$ samples for each formulation were dried in an oven at $50{ }^{\circ} \mathrm{C}$ for $24 \mathrm{~h}$, after cooled in a desiccator and weighed $\left(t_{0}\right)$. Then, the specimens were immersed in distilled water and maintained at room temperature for $24 \mathrm{~h}$. The samples were removed from water after $24 \mathrm{~h}$, wiped with a dry towel, weighed and then immediately immersed again in distilled water. The percentage of water absorption was calculated using the next equation:

$$
\text { Increase in weight, } \%=\frac{\text { wet weight-conditioned weight }}{\text { conditioned weight }} \times 100
$$

\subsection{Chemical Resistance Test}

The chemical stability of the prepared thermosets was tested in different solvents as acetone, toluene, methanol, acetonitrile, dimethylformamide, dimethyl sulfoxide, chloroform and tetrahydrofuran. In the first step, the samples, with $15.5 \times 15.5 \times 4.5 \mathrm{~mm}^{3}$ dimensions were weighed and then immersed in $20 \mathrm{ml}$ of solvent. After $24 \mathrm{~h}$, the samples were removed from solvents, wiped with dry clothes, weighed and then immediately immersed in the recipient with solvent. The samples stability against the solvents was determined visually, but also quantitatively using the following equation:

$$
\text { Weight, } \%=\frac{\text { wet weight-conditioned weight }}{\text { conditioned weight }} \times 100
$$

\subsection{Bio-Based Carbon Content}

The bio-based carbon content of the materials was determined according with the paper of Pan et al. (Pan, Sengupta, $\&$ Webster, 2011). Humins and triglycidyl ether of phloroglucinol are $100 \%$ bio-based. Firstly, the percentage of carbon was determined for each compound, then the bio-based carbon content for the three formulations was calculated based on their mass weight.

\section{Results and Discussions}

\subsection{DSC Study of the Humins - TGPh Copolymerization Reactions}

The first objective of this work focused on establishing the thermodynamical parameters of copolymerization reactions and crosslinking but also on the elaboration of the optimal compositions for the development of the humins-based sustainable materials. The proof of the copolymerization, the chemical connectivity between the two comonomers, their molecular structure and their reactivity were elucidated by ATR-FTIR and NMR spectroscopies in our previous study (Cantarutti et al., 2019). In order to study the thermodynamic processes of the copolymerization, different formulations, in different ratios of humins, TGPh and BDMA/DMP-30 were studied by DSC. Firstly, mixtures between humins and TGPh in different ratios were analyzed to select the optimal 
ratios for the development of new resins. In Figure 1 are revealed the DSC thermograms during heating of humins/TGPh reactive mixtures without catalyst or accelerator.

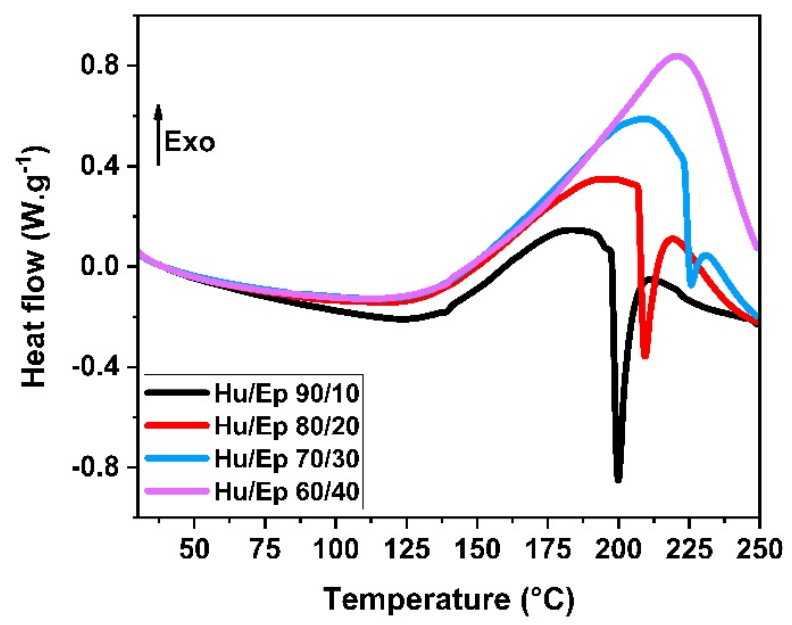

Figure 1. DSC thermograms obtained during heating at $10{ }^{\circ} \mathrm{C} \cdot \mathrm{min}^{-1}$ of humins/epoxide reactive mixtures at different ratios $(\mathrm{w} / \mathrm{w} \%)$, without catalyst or accelerator

An important objective in this study is the valorization in large quantities of the humins, the biorefineries' sideproduct. Considering this aspect, four different ratios, in which humins represents the major compound of the mixture, were tested. In Figure 1 we can observe that all four mixtures have a good humins vs. epoxy reactivity even if in these systems we didn't used any catalyst. Although the reactivity between the two compounds is present, in the case of mixtures with 10-30 wt.\% TGPh, the appearance of an endothermic peak between $200-230^{\circ} \mathrm{C}$ can be observed in Figure 1 thermograms. These peak displays that the amount of epoxy compound is insufficient for the complete crosslinking of humins, so the unreacted humins begins to degrade at around $200{ }^{\circ} \mathrm{C}$. This behavior was confirmed by TGA analysis, not presented here. As can be seen in Figure 1, the mixture with $60 \mathrm{wt} . \%$ humins and $40 \mathrm{wt} . \% \mathrm{TGPh}$ (purple line) reveal a good reactivity and the degradation of humins is not anymore present. To optimize the crosslinking process, i.e. to decrease the reaction temperature interval so also the maximum crosslinking temperature, different catalyst/accelerator ratios were tested. The DSC thermograms of the evolution of different mixtures in function of temperature are presented in Figure 2, and the values of the copolymerization's enthalpies and temperatures of reaction are summarized in Table 1.

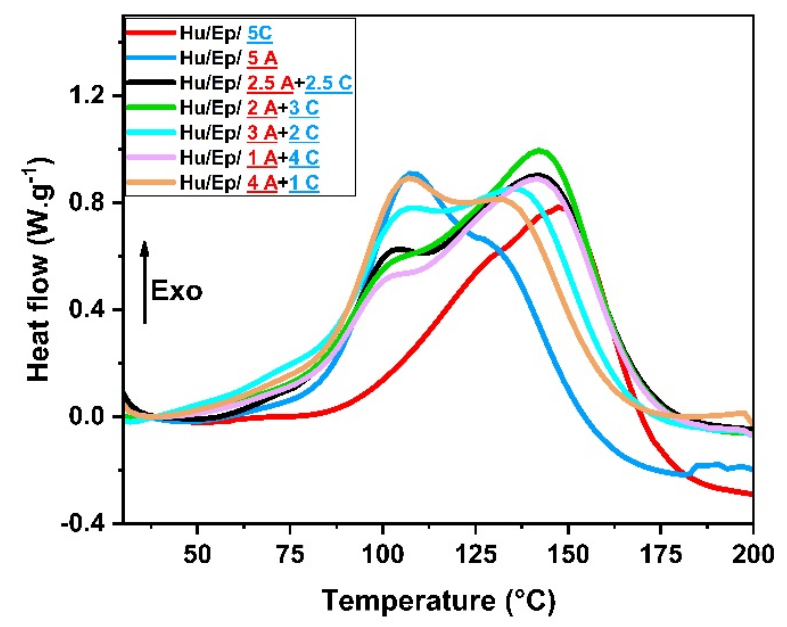

Figure 2. DSC thermograms during heating at $10{ }^{\circ} \mathrm{C} \cdot \mathrm{min}^{-1}$ of humins-TGPh copolymerization systems at different $\%$ ratios accelerator $(\mathrm{A})$ and catalyst $(\mathrm{C})$ 
It can be observed that the addition of the catalyst and accelerator improves the copolymerization reactivity and decreases considerably the onset of thermal reactions and the $T_{\max }$ of the reactions. In the presence of the activating species, i.e. the catalyst and/or the accelerator, a complex reactivity is exhibited in all the formulations since two exothermic peaks can be observed in Figure 2. A first exothermal reaction occurs at around $100^{\circ} \mathrm{C}$. This reaction occurs very fast, with a rapid increase of the curve's slope and could be mainly attributed to the accelerator's contribution on the crosslinking. In the presence of the accelerator the TGPh ring opening occurs very fast promoting both TGPh homopolymerization and crosslinking via-OH functions from the humins (Cantarutti et al., 2019). The second reaction occurs at around $140-148{ }^{\circ} \mathrm{C}$ (depending on the system) and is mainly the result of the catalyst contribution on the copolymerization. In our previous study of chemical mechanism of this copolymerization, an anionic mechanism of polymerization is involved. In the presence of the catalyst the initiation is the determinant step with the nucleophilic attack of the BDMA to the epoxy ring from TGPh. Then, the propagation occurs via a transfer proton between the TGPh adduct and the $-\mathrm{OH}$ from the humins. The copolymerization reactions is accompanied by humins structural rearrangements $\gamma$-keto acid cyclization, $\gamma$-keto esterification, favored at high temperatures $\left(>130^{\circ} \mathrm{C}\right)$ (Cantarutti et al., 2019). We can notice that in the systems containing both activating species we can identify an additional contribution of each species.

Three different formulations were selected to be developed and analyzed: like the mix with $5 \mathrm{wt} \%$ catalyst (BDMA), that with $5 \mathrm{wt} . \%$ accelerator (DMP-30) and the equal combination between the two $(2.5 / 2.5 \mathrm{wt} . \%)$. The obtained DSC results show that the addition of $5 \mathrm{wt} . \%$ BDMA or $5 \mathrm{wt} . \%$ DMP-30 produce reactions with similar enthalpy values $\left(\approx 290 \mathrm{J.g}^{-1}\right)$ and intervals of temperature between $45^{\circ} \mathrm{C}$ to $190^{\circ} \mathrm{C}$. The difference appears in the $\mathrm{T}_{\max }$ of the reactions that is around $106^{\circ} \mathrm{C}$ for the system with accelerator, HuEpA, but much higher $148{ }^{\circ} \mathrm{C}$ for the system with catalyst, HuEpC. The third selected formulation containing the 2.5/2.5 wt.\% of BDMA/DMP-30 combination reveals the highest enthalpy of reaction $\approx 365 \mathrm{J.g}^{-1}$. The onset of crosslinking for HuEpAC is at $40^{\circ} \mathrm{C}$, reaching the maximum rate at $142{ }^{\circ} \mathrm{C}$. It can also be seen for this formulation that the crosslinking's completion is similar with that of $\mathrm{HuEpC}$ and HuEpA systems, the DSC heat flow reaching a quasi-linear response at $\approx 195^{\circ} \mathrm{C}$.

Table 1. DSC results of the humins/TGPh copolymerization at different catalyst/accelerator ratios

\begin{tabular}{|c|c|c|c|c|c|c|c|}
\hline & $\begin{array}{c}\mathrm{Hu} / \mathbf{E p}- \\
\underline{5 \mathrm{C}}\end{array}$ & $\begin{array}{c}\mathrm{Hu} / \mathbf{E p}- \\
\underline{\mathbf{5 A}}\end{array}$ & $\begin{array}{c}\text { Hu/Ep- } \\
\underline{2.5 \mathrm{~A}}+\underline{2.5 \mathrm{C}} \\
\end{array}$ & $\begin{array}{c}\text { Hu/Ep- } \\
\underline{2 A}+\underline{3 C}\end{array}$ & $\begin{array}{c}\text { Hu/Ep- } \\
\underline{3 A}+\underline{2 C}\end{array}$ & $\begin{array}{c}\text { Hu/Ep- } \\
\underline{1 \mathrm{~A}}+\underline{4 \mathrm{C}}\end{array}$ & $\begin{array}{l}\mathrm{Hu} / \mathrm{Ep}- \\
\underline{4 \mathrm{~A}}+\underline{1 \mathrm{C}} \\
\end{array}$ \\
\hline Reaction $\boldsymbol{T}_{\max }$ (interval) $\left({ }^{\circ} \mathrm{C}\right)$ & $\begin{array}{c}148 \\
(54-193)\end{array}$ & $\begin{array}{c}106 \\
(45-182)\end{array}$ & $\begin{array}{c}142 \\
(38-194)\end{array}$ & $\begin{array}{c}143 \\
(38-198)\end{array}$ & $\begin{array}{c}136 \\
(34-190)\end{array}$ & $\begin{array}{c}142 \\
(42-188)\end{array}$ & $\begin{array}{c}108 \\
(38-183)\end{array}$ \\
\hline Enthalpy of reaction $\left({\left.\mathrm{J} . \mathrm{g}^{-1}\right)}^{-}\right.$ & 276 & 294 & 365 & 350 & 333 & 321 & 313 \\
\hline
\end{tabular}

\subsection{Physico-Chemical and Mechanical Properties of Bio-Based Thermosets}

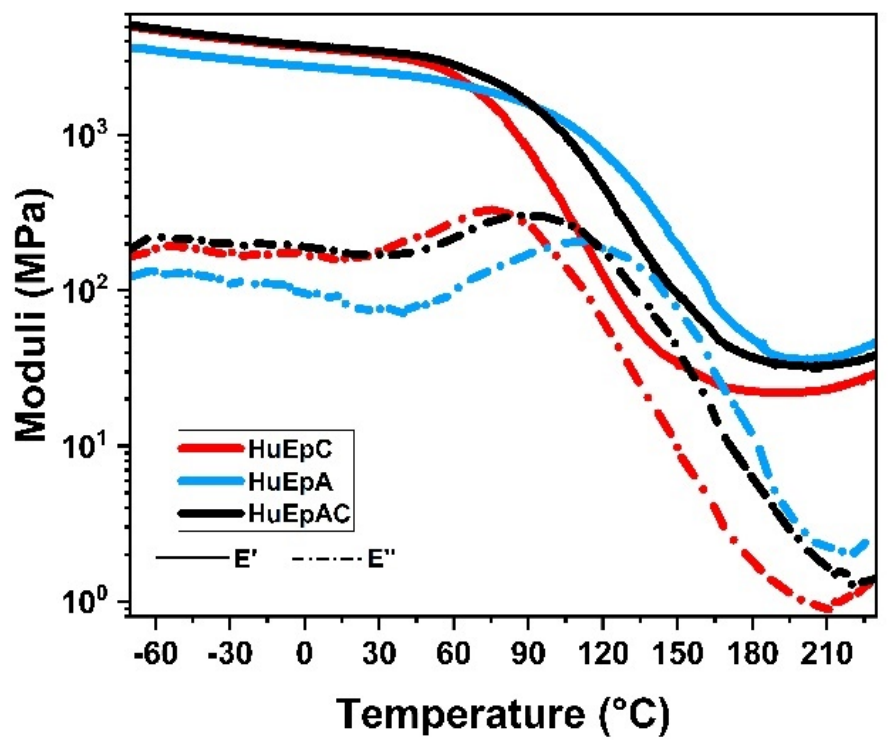

Figure 3. Viscoelastic behavior as a function of temperature for storage (continuous line) and loss (dotted line) moduli as results measured by DMA of the three humins-based thermosets 
Dynamic mechanical analysis was used to investigate the correlation between the three selected formulations on the materials properties. The three systems selected here aim to highlight the influence of the copolymerization initiation step on the viscoelastic behavior of final materials. Even if the overall chemical mechanism of reactions is very complex in the case of humins macromonomer, through these three systems we can observe that the obtained materials have differences in their thermomechanical behavior, so different copolymers' network structure.

The DMA tool was used in particular to determine materials' stiffness and mechanical damping characteristics. For polymers' applications the stiffness represents the parameter of prime importance. The moduli of polymers show strong dependence on temperature (Ebewele, 2000), such that the effect of temperature on the elastic response ( $E^{\prime}$ - storage modulus) and on the viscous response ( $E^{\prime \prime}$ - loss modulus) of the three thermoset materials were analyzed. In the Figure 3 are depicted the moduli vs. temperature curves for the three obtained thermosets, in which three regions of viscoelastic behavior are evident: a glassy region followed by a transition from the glassy to rubbery and finally the rubbery plateau.

The storage modulus is continuously decreasing with the temperature between -75 to $200{ }^{\circ} \mathrm{C}$, behavior explained by the increasing of the chains free volume with the thermal expansion. The two materials containing the catalyst (HuEpC and HuEpAC) have similar E' values in the glassy region of $\approx 5 \mathrm{GPa}$, while for material with the accelerator $(\mathrm{HuEpA})$ the value of $\mathrm{E}^{\prime}$ decreases at $\approx 3.7 \mathrm{GPa}$. Although the resin only with accelerator has a low value of the storage modulus in the glassy region, the onset of its drop to the rubbery region occurs at higher temperature compared to the thermoset prepared with the BDMA catalyst. The elastic response of the resins in the rubbery region depends highly on the density of the materials crosslinks. The smallest drop interval value between the glassy and rubbery region appears for the system with the accelerator, the HuEpA thermoset, $(\approx 40 \mathrm{MPa})$, thus presenting the highest crosslink density. This value is followed by that of HuEpAC resin ( $35 \mathrm{MPa})$, the last being the formulation developed only with the catalyst $(\approx 26 \mathrm{MPa})$. The crosslink densities values and the average molecular weight between crosslinks (Mc) of the humins-based resins were also calculated and given in Table 2 . A significant mechanical parameter that should be considered in products' design and development is represented by their brittleness (B). According with studies developed by W. Brostow et al. (Brostow \& Hagg Lobland, 2010; Brostow, Hagg Lobland, \& Narkis, 2006; Brostow, Hagg Lobland, \& Narkis, 2011), the storage modulus (E') of the materials is inversely proportional to brittleness (B), which means that the humins-based resins with high storage modulus such as HuEpC and HuEpAC, are less fragile compared to HuEpA material.

Since the viscoelastic properties of the thermosets vary with both temperature and time, the study of time dependence or frequency of viscoelasticity was performed for the materials characterization. The viscoelastic curve, called master-curve is using the Time-Temperature Superposition principle (Brostow, 2009; Menard, 2008). The mechanical properties of the three humins-based resins were analyzed by DMA in the frequency range $10 \mathrm{~Hz}$ to $0.1 \mathrm{~Hz}$ at a logarithmic increment of 10 steps/decade, under isothermal conditions at different temperatures between $-25^{\circ} \mathrm{C}$ to $250^{\circ} \mathrm{C}$. The obtained dynamic mechanical data were collected, and the storage moduli plotted as a function of frequency. To obtain the master-curves for each thermoset, each isotherm was shifted (left or right) $=\mathrm{f}(\log$ frequency $)$ axis relative to the reference temperature $T_{\text {ref }}=125^{\circ} \mathrm{C}$. Figure 4 shows the storage modulus master curve for each humins-based thermoset materials.

The storage modulus curves obtained at $T>T_{\text {ref }}$ were moved at lower frequencies, and the curves measured at $T<$ $T_{\text {ref }}$ were moved at higher frequencies in order to achieve the maximum data overlap. The shifting of the curves was done in this way to ensure that each curve fits the slope of its immediate neighbor. The master curves for all the three humins-based thermosets were generated in order to understand the effect of crosslink densities of the networks on the viscoelastic properties of the materials. From Figure 4 it can be seen that the viscoelastic transition region of the thermoset resins was shifted to higher frequency scales with the decrease of the crosslink density (Table 2) of the bio-resins.
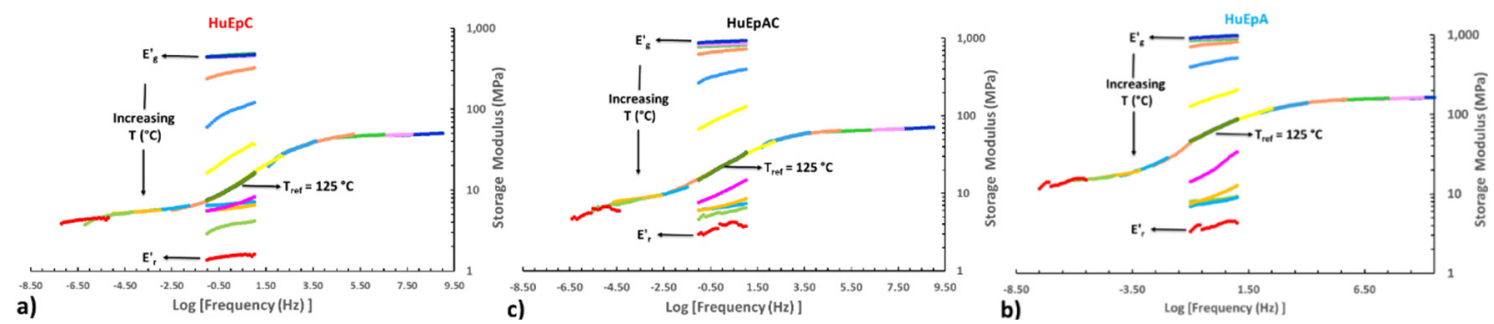
Figure 4. Master curve of storage modulus of humins/epoxy thermosets: a) HuEpC, b) HuEpA, c) HuEpAC obtained after using common shift factor

Another important parameter that generates valuable information regarding the physico-chemical and mechanical properties of the polymers is represented by the glass transition region of the materials. It is known that the glass transition of the materials is not only a value of the transition between the states of thermodynamic equilibrium and is represented by the reversible transition interval from a hard and relatively fragile state into a molten or rubbery state. The glass transition is a dynamic phenomenon being directly dependent on physico-chemical and mechanical factors such as the thermal history of the material, rate of temperature and also the standard/technique used for characterization (Kalogeras \& Hagg Lobland, 2012). According with ASTM E1640-13 and ASTM D7028-07 (ASTM-D7028, 2008; ASTM-E1640, 2013) the glass transition region of the materials can be determined from the DMA results using three different methods like the onset of the storage modulus drop ( $T_{g}$ onset $)$, the peak of the maximum of the loss modulus $\left(T_{g \text {-loss }}\right)$, and the maximum value of the damping factor $(\tan \delta)$. A common technique to determine the glass transition phenomenon $\left(T_{g}\right)$ of the materials is the DSC. The glass transition obtained by DSC and the transitions resulting from DMA analysis are used as synonyms because both are trying to model the same molecular phenomenon namely the coordinated chain motions in the network. Meanwhile, the $T_{g-D S C}$ is measured under no mechanical stress being just the effect of the temperature on the chains mobility, the transitions by DMA are measured under mechanical stress at a given frequency. The obtained values could be quite different depending on the frequency used for mechanical stress (Fache, Viola, Auvergne, Boutevin, $\&$ Caillol, 2015). The evolutions of the $\tan \delta$ of the humins-based materials in function of the temperature are plotted in Figure 5 and the $T_{g}$ values obtained by DMA and DSC summarized in Table 2.

We can notice that the lowest $\tan \delta$-maxima value is that of the resin prepared with the catalyst (BDMA), $\tan \delta \approx$ $122{ }^{\circ} \mathrm{C}$, followed by that of HuEpAC material $\left(\tan \delta \approx 144{ }^{\circ} \mathrm{C}\right.$ ). The highest $\tan \delta$ value was obtained by the resin prepared with accelerator, $\tan \delta \approx 157^{\circ} \mathrm{C}$. The temperature range of $\tan \delta$ peak for three thermosets is similar, having the onset at $\approx 15^{\circ} \mathrm{C}$ and the end set at around $225^{\circ} \mathrm{C}$. This broad interval of the $\alpha$ relaxation peak $\left(\approx 210^{\circ} \mathrm{C}\right)$ indicates a large distribution of the relaxation times, characteristic for the complex, heterogeneous networks with dangling chains. The $T_{g \text {-onset }}$ region obtained from $\mathrm{E}^{\text {' and }} \mathrm{T}_{\mathrm{g} \text {-loss }}$ from $\mathrm{E}$ " revealed the same trend as the $\mathrm{T}_{\mathrm{g}}$ range given by $\tan \delta$-maxima. So, according with these values the most rigid of the three thermosets is that obtained with the accelerator followed by the resin made with the combination catalyst + accelerator and the last being the thermoset with BDMA. Corroborating these results with that of the DSC analysis of crosslinking we can observe that the accelerator starts a rapid crosslinking, at lower temperature, through a complex mechanism of curing via nucleophilic attack on the humins and or TGPh accompanied by structural rearrangements on the humins frame. The obtained thermosets show higher $\tan \delta$ value then the system where the copolymerization follows the catalyst's initiation by a nucleophilic attack on the epoxide ring of TGPh and anionic copolymerization.

Table 2. Calculated and measured parameters for the humins-based thermosets

\begin{tabular}{|c|c|c|c|c|c|c|c|c|}
\hline \multirow[b]{2}{*}{ Sample } & \multirow[b]{2}{*}{ Density $\left(\mathrm{g} / \mathrm{cm}^{3}\right)$} & \multirow[b]{2}{*}{$v\left(\mathbf{m m o l} \cdot \mathrm{cm}^{-3}\right)$} & \multirow[b]{2}{*}{$\begin{array}{c}\text { Mc } \\
(\mathrm{g} / \mathrm{mol})\end{array}$} & \multicolumn{4}{|c|}{ Glass transition $\left({ }^{\circ} \mathrm{C}\right)$} & \multirow{2}{*}{$\begin{array}{c}\text { Hardness } \\
\text { test } \\
\text { Shore D }\end{array}$} \\
\hline & & & & $\tan \delta$ & $\begin{array}{c}\mathrm{T}_{\text {g-onset }} \\
\text { (DMA) }\end{array}$ & $\begin{array}{c}\mathrm{T}_{\text {g-loss }} \\
\text { (DMA) }\end{array}$ & $\begin{array}{l}T_{g-D S C} \\
\text { (DSC) }\end{array}$ & \\
\hline HuEpC & 1.14 & 2.42 & 469 & 122 & 70 & 77 & 52 & 82 \\
\hline HuEpA & 1.13 & 3.66 & 308 & 157 & 107 & 114 & 60 & 87 \\
\hline HuEpAC & 1.14 & 3.11 & 365 & 144 & 86 & 97 & 56 & 85 \\
\hline
\end{tabular}

The DMA results allowed us also to calculate the crosslink density $(v)$ of the thermosets based on the equation:

$$
v=\frac{E^{\prime}}{3 R T}
$$




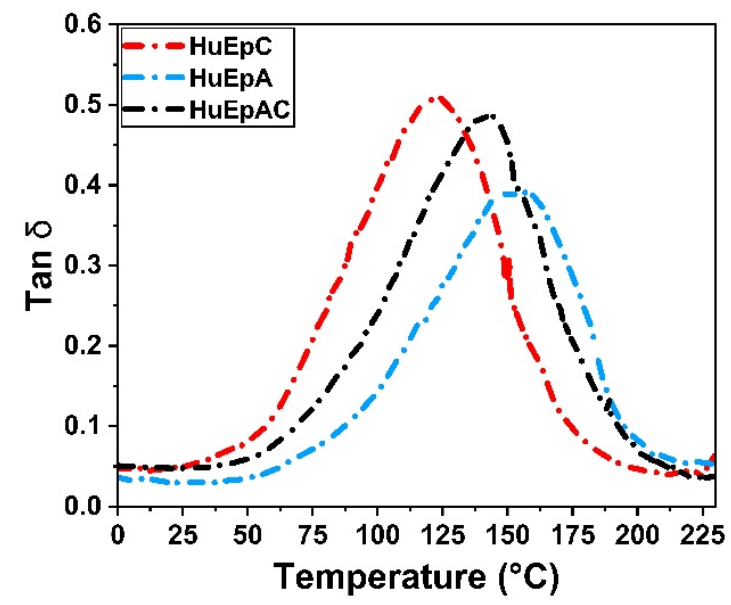

Figure 5. Loss factor $(\tan \delta$ ) plots as function of temperature determined by DMA for the three thermosets: HuEpC (red line), HuEpA (blue line), HuEpAC (black line)

where $E^{\prime}$ is the storage modulus of thermoset in the rubbery plateau region at $T_{g}+85^{\circ} \mathrm{C}(\mathrm{MPa}), R$ is the gas constant, and $T$ is the absolute temperature (K) (Flory, 1953). The crosslink density of the material is a parameter directly correlated, proportional with its hardness, moduli, mechanical strength and chemical resistance, while the elongation at break or impact strength have opposite trend (Ratna, 2009). Also, the average molecular weight between crosslinks $\left(M_{c}\right)$ is a measure of the crosslink density, such that the lower $M_{c}$ value, the higher the crosslink density. The average molecular weight between crosslinks is given by:

$$
M c=\frac{3 \rho R T}{E \prime}
$$

where $\rho$ represents the density of the resin $\left(\mathrm{g} / \mathrm{cm}^{3}\right), R$ is the gas constant, $T$ is absolute temperature $(\mathrm{K})$, and $E$ ' is the storage modulus of thermoset in the rubbery plateau (MPa) (Ratna, 2009). In the same time the crosslinking density of a material is related to the amplitude of $\tan \delta$ (Figure 5): higher is the peak amplitude smaller is the crosslink density and the resin is more rigid. As can be seen, in Table 2 the properties resulting from different analyses techniques and the calculated ones are in agreement and have the same tendency. Comparing the mechanical properties of the three bio-based resins developed in this study with those stipulated in literature or industry, it can be said that the humins/TGPh-based resins could compete very well the industrial thermosets produced from fossil resources (Cambridge University Engineering Department, 2003; "Hardness Shore D," n.d.; Ma et al., 2013).

The evolution of the $T_{g-D S C}$ in function of the heating rate was also studied in oxidative atmosphere, the obtained DSC thermograms being presented in Figure 6. The materials present the same trend confirming the results obtained by DMA. The material obtained with the accelerator has the highest $T_{g-D S C}$, between $56-70^{\circ} \mathrm{C}$ (in function of the heating rate), thus being the most rigid of the three resins studied in this work. Moreover, the rigidity of the humins-based thermoset was evaluated by the hardness tests using the Shore D scale. The obtained results are also given in Table 2 and show that the materials' rigidity follow the same trend as the $T_{g}$, increasing in the following order: $\mathrm{HuEpC}<\mathrm{HuEpAC}<\mathrm{HuEpA}$. According with the Shore D results, the hardness of the three thermosets is characteristic to hard materials, the obtained values being comparable with that of commercial materials (ABS High Impact: 75-85SD, PAN: 85-93SD, PET: 85-95SD, PFA:60-65SD, PTFE: 50-65SD ) ("Hardness Shore D," n.d.; Vian \& Denton, 2018). 

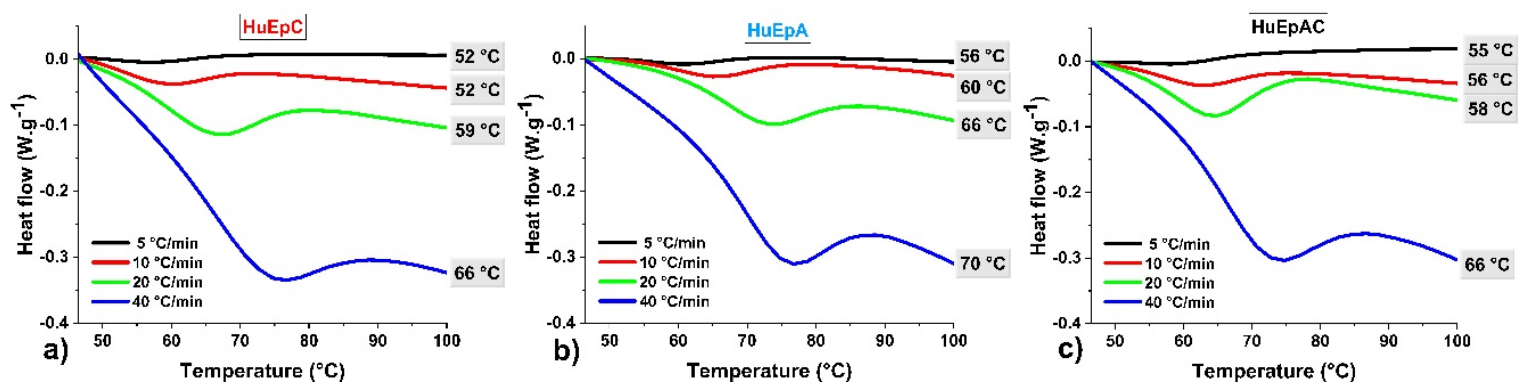

Figure 6. The evolution of the glass transition ( $T_{\mathrm{g}}$ ) in function of heating rate for a) $\left.\mathrm{HuEpC}, \mathrm{b}\right) \mathrm{HuEpA}$ and c) HuEpAC obtained by DSC

\subsection{Thermal Stability of Thermosets}

Thermogravimetric analyses were performed under air and nitrogen atmosphere in order to determine the thermooxidative and thermal stability of the three thermoset materials. The TGA thermograms as recorded from continuous heating under air flow are plotted in Figure 7.

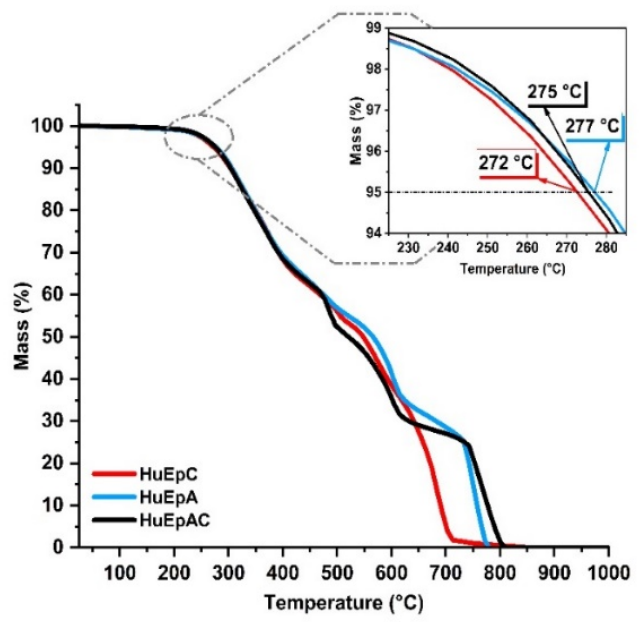

Figure 7. Thermo-oxidative stability of the bio-based humins resins: HuEpC (red line), HuEpA (blue line),

HuEpAC (black line); TGA run at $10^{\circ} \mathrm{C} \cdot \mathrm{min}^{-1}$ under air flow

According with the obtained data, the bio-based thermosets reveal a good thermal stability, the degradation process is accompanied by volatiles release ( $5 \%$ mass loss) at around $280{ }^{\circ} \mathrm{C}$ under air. Based on the number of peaks in the DTG thermograms (not presented here) the decomposition process shows the presence of three major stages. This multi-stage decomposition can be explained by the complex profile of humins-based thermosets and also by their heterogeneous structure, as already highlighted by the broad $\tan \delta$ peaks. The first step represents the major thermal decomposition stage for all the three resins, the thermolysis. In this step, the mass loss of the HuEpC resin is approximately $38 \%$ of the initial mass and the end temperature of this degradation occurs at around $450{ }^{\circ} \mathrm{C}$. For the other two resins, with the accelerator, this interval of temperature is larger, ending at around $550{ }^{\circ} \mathrm{C}$, with 45 $47 \%$ mass loss. This observation indicates that the thermosets produced in presence of the accelerator are more heterogeneous and more susceptible to thermolysis. In the second step of decomposition the HuEpC resin lost $28 \%$ of mass between $450-620^{\circ} \mathrm{C}$, while the resins only with the accelerator or combined with the catalyst lost $23 \%$ and $28 \%$ respectively in the range $500-700{ }^{\circ} \mathrm{C}$. The third decomposition is thermal-oxidation and carbonization of the materials.

It is known that the decomposition mechanism and the shape of TGA curves can be influenced by different factors, one of the primary factors being the heating rate of the samples. As the heating rate increases, the decomposition temperature of the sample also increases (Ratna, 2009). The three bio-based thermosets were investigated under nitrogen flow in four different heating rates between $5-40{ }^{\circ} \mathrm{C} \cdot \mathrm{min}^{-1}$ in order to analyze the influence of this factor on the thermal stability of the materials. TGA thermograms under nitrogen can be seen in Figure 8 and the results are given in Table 3. 

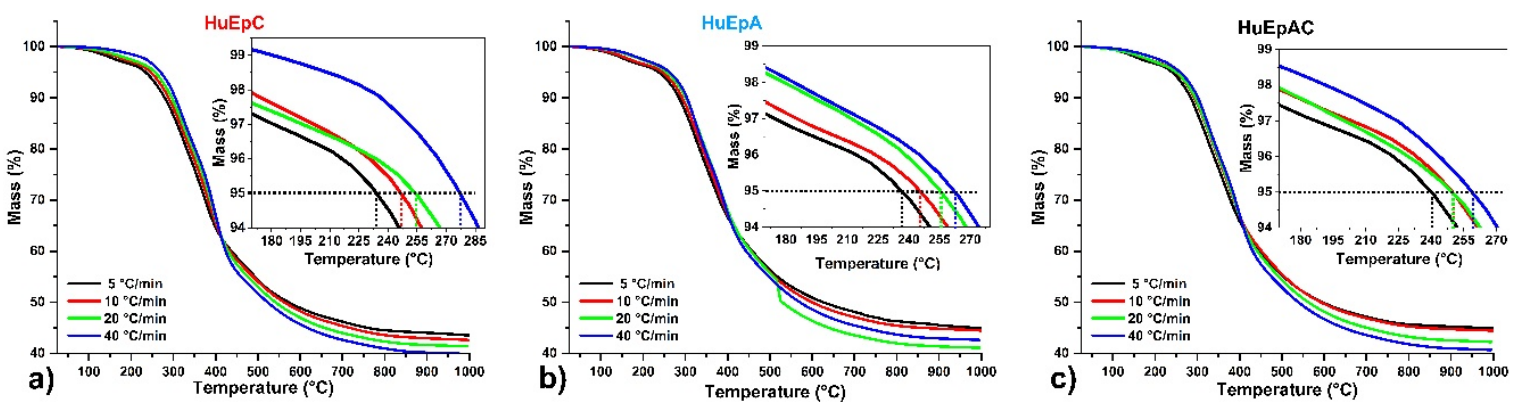

Figure 8. TGA curves at different heating rates under nitrogen flow for the cured humins: a) HuEpC; b) HuEpA; $\mathrm{HuEpAC}$

The thermograms in inert atmosphere show a one stage degradation mechanism and a small shoulder between $150-200{ }^{\circ} \mathrm{C}$ which gradually disappears as the heating rate increases. This very small weight loss can be due to the evaporation of moisture or other volatile compounds present in the materials. As expected, by increasing the heating rate the materials start to decompose at higher temperatures.

Table 1. Temperatures of thermal degradation $\left(T_{5 \%}\right)$ of the cured humins bio-based thermosets under inert atmosphere and at different heating rates: a) $\mathrm{HuEpC}$ resin; b) $\mathrm{HuEpA}$ resin and c) $\mathrm{HuEpAC}$ resin

\begin{tabular}{lcccc}
\hline & \multicolumn{2}{c}{$\boldsymbol{T}_{5 \%}\left({ }^{\circ} \mathbf{C}\right)$ under nitrogen flow } \\
& $5^{\circ} \mathrm{C} \cdot \mathrm{min}^{-1}$ & $10^{\circ} \mathrm{C} \cdot \mathrm{min}^{-1}$ & $20^{\circ} \mathrm{C} \cdot \mathrm{min}^{-1}$ & $40^{\circ} \mathrm{C} \cdot \mathrm{min}^{-1}$ \\
\hline HuEpC & 232 & 245 & 255 & 270 \\
HuEpA & 233 & 243 & 255 & 265 \\
HuEpAC & 241 & 251 & 250 & 258 \\
\hline
\end{tabular}

Figure 8 reveals that although the increase of the heating rate improves the thermal stability of the materials at the beginning of degradation, at $T>450^{\circ} \mathrm{C}$ this factor influences negatively, the thermal stability decreasing. Another fact that show the influence of the analysis parameters on the materials properties is that the heating rate of $5{ }^{\circ} \mathrm{C} \cdot \mathrm{min}^{-1}$ in nitrogen increase the $T_{5 \%}$ temperature of the resins in the following order of HuEpC $<\mathrm{HuEpA}<$ HuEpAC, while at $40{ }^{\circ} \mathrm{C} \cdot \mathrm{min}^{-1}$ the increase is in the opposite direction. The thermal stabilities of the three humins/epoxy thermosets are improved compared to that of the furan/epoxy bio-resins stipulated in literature $\left(T_{5 \%}=\right.$ 141-221 ${ }^{\circ} \mathrm{C}$, under air) (Liu et al., 2017; Monti, Hoydonckx, Stappers, \& Camino, 2015; Nouailhas et al., 2011), the resulting values being comparable with those of commercial epoxy resins (Chairat et al., 2015; Zhu et al., 2011).

\subsection{Water Absorption Analysis}

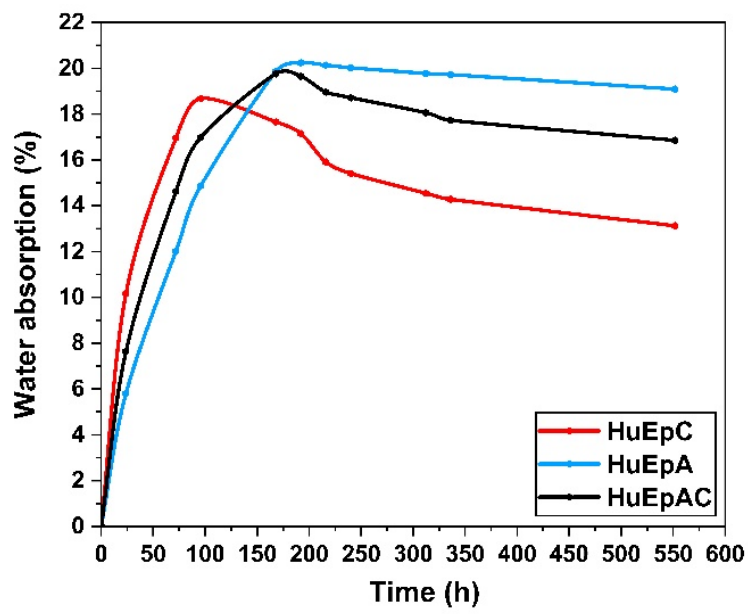

Figure 9. Water absorption \% in function of time; Comparison between the three humins-based resins 
To study the water absorption behavior the three thermosets were immersed in deionized water at $25{ }^{\circ} \mathrm{C}$, and the weight variation was evaluated over time. The evolution of the water sorption is given in Figure 9. The water retention by the thermosets is influenced by numerous factors as the network architecture (mass between crosslinking nodes, crosslinking density, free volume, etc.) and by the chemical nature of the components (polar groups) (Chen, Xi, \& Zhao, 2016; L. Li, Yu, Wu, Zhan, \& Li, 2009). After $24 \mathrm{~h}$ of immersion in deionized water, the percentage of absorbed water is $\approx 5-10 \%(\mathrm{w} / \mathrm{w})$, equivalent with the commercial epoxy values $\left(\mathrm{WA}_{\text {Fiberite }} 934\right.$ $=6.95 \%$, $\left.\mathrm{WA}_{\text {Ciba Geigy MY720 }}=6.8 \%\right)($ Bouvet et al., 2015; Zhou \& Lucas, 1999).

In Figure 9 it can be observed that the water absorption of the three resins increase in time reaching a maximum point after $96 \mathrm{~h}$ for HuEpC, $192 \mathrm{~h}$ for HuEpA and $168 \mathrm{~h}$ for HuEpAC. The obtained values are again in good accord with the previous results. We can notice that the thermosets prepared with the catalyst, characterized by the lower $T_{g}$ value and lower degree of crosslinking exhibit the faster water absorption (abrupt slope of the curve). Then, probably the water absorbed molecules block at a certain point the access to the network free volume and the absorption is stop after $75 \mathrm{~h}$ reaching $19 \%$. The system with the accelerator has a slower kinetic of water absorption with a maximum reached after $170 \mathrm{~h}$ at around $20 \%$. These values are directly correlated with the materials crosslink densities but also with the number of the free hydroxyl or other polar groups present in the humins-based resins which can increase the water absorption by hydrogen bonding with water. After reaching the maximum absorption value, the water uptake decreases until reached a steady state.

\subsection{Chemical Resistance of the Bio-Based Thermosets}

a)

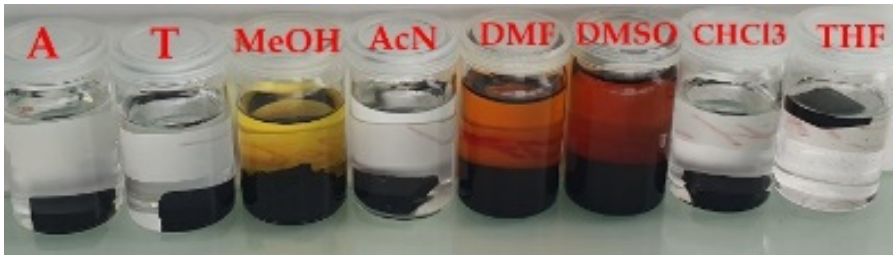

b)

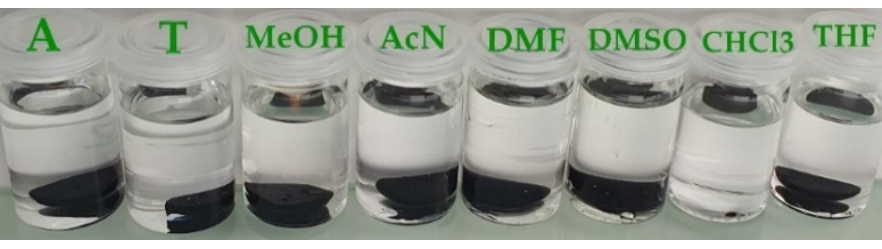

c)

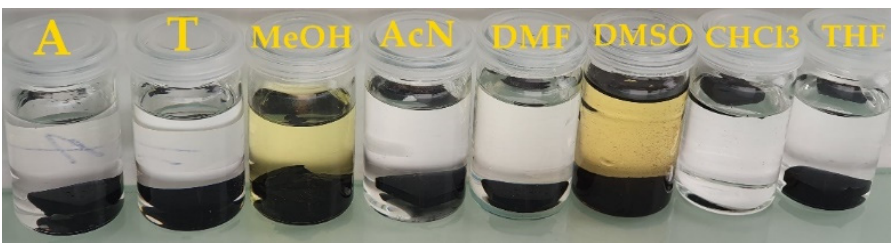

Figure 10. Comparison of chemical stability after immersion in different solvents for 12 days of three resins: a) HuEpC, b) HuEpA, c) HuEpAC

Generally, the exposure of polymeric materials to chemical reagents influences and affects the overall properties but especially the mechanical ones. In order to highlight the influence of the chemical reagents on the humins biobased resins, the three materials were tested in a large variety of solvents like acetone (A), toluene (T), methanol $(\mathrm{MeOH})$, acetonitrile $(\mathrm{AcN})$, dimethylformamide (DMF), dimethyl sulfoxide (DMSO), chloroform (CHCl3) and tetrahydrofuran (THF) in order to cover a wide range of polar or apolar reagents. Samples in rectangular shape of each type of formulation were immersed in transparent vials with $20 \mathrm{ml}$ solvents and weighed regularly each $24 \mathrm{~h}$. The solvents resistance tests were performed for 12 days, because after this time the humins-based materials became stable, gaining a steady state. In Figure 10 can be visualized the appearance of the three resins in different solvents at the end of the experiment (12 days). Considering these results, we can appreciate that the thermosets prepared with the accelerator has the best resistance to the chemical reagents. Again, this finding could be explained by its highest degree of crosslinking, rigidity and stiffness. On the contrast, the thermoset prepared with the catalyst seems the most affected by the polar solvents by small defragmentation in $\mathrm{MeOH}$, being more evident in DMF and DMSO. In the case of the resin with the catalyst + accelerator, a very small decomposition of the material in $\mathrm{MeOH}$ and DMSO is observed, in the rest of the solvents being completely resistant. The comparison 
between these systems is a clear sign that humins/epoxy materials have a different network architecture, chemical bonding and also free functional groups. So, even if the starting comonomers are the same, the nature of the initiator influences drastically the network structure and the overall properties. After 12 days no evolution of the samples occurred.

Figure 11 illustrates the influence of solvents on the weight of bio-based resins, where a positive value implies a weight gain, while a negative value implies a weight reduction. In accordance with the experimental results, it can be observed that the HuEpC resin (red line) present a significative weight loss in $\mathrm{MeOH}(20.17 \mathrm{wt} . \%$ ), in DMF (44.95 wt.\%), but especially in DMSO (47.77 wt.\%). In contrast, the HuEpA resin (blue line) does not lose weight in any of the seven solvents tested, instead this material absorbs small amounts of solvent between $0-0.8 \%$ exception the sample immersed in $\mathrm{MeOH}$ showing an increase in weight up to $8 \%$.

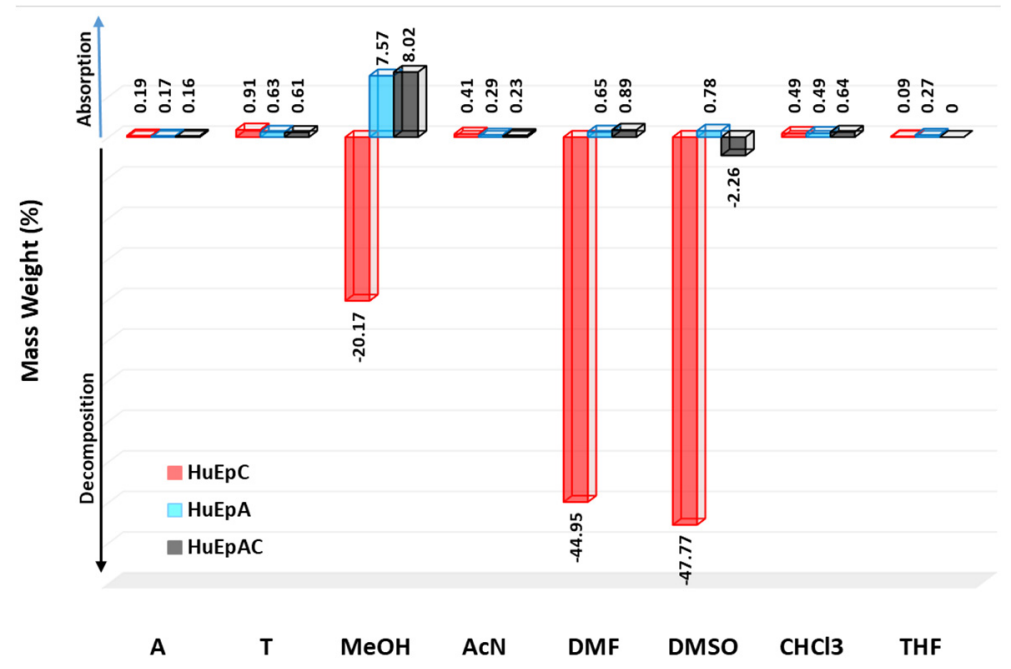

Figure 11. Influence of solvents on the humins/TGPh materials' weight after $288 \mathrm{~h}$ of immersion at room temperature

\subsection{Bio-Based Content of Humins/TGPh Copolymers}

In the last period, a great emphasis is focusing on the development of materials from bio-renewable sources, and on increasing their bio-based content. The bio-based content of a product was defined in 2005 by the US Department of Agriculture (Norton \& Devlin, 2006) as the amount of bio-based carbon in the material or product as a percentage of the weight (mass) of the total organic carbon in the product. Considering that the structure of humins cannot be precisely defined, so the reaction mechanism accurately quantified, the bio-based carbon content of the three resins was calculated according to previous studies (NCS-16785, 2016; Pan et al., 2011). Both humins and TGPh are products made from renewable raw materials, so they are $100 \%$ bio-based, while BDMA and DMP30 are $100 \%$ petrochemical-based compounds. According to previous studies done on biorefinery humins (Muralidhara, Bado-Nilles, et al., 2018; Muralidhara, Tosi, et al., 2018), it is known that the bio-based carbon of the raw humins is around 54\%. Considering the molar mass and the number of carbons in each compound we calculate its carbon percentage. The bio-based carbon content by weight was calculated using the equation:

$$
B C C=\frac{\sum\left(W_{100 \%} \cdot T C_{100 \%}\right)}{\sum\left(W_{100 \%} \cdot T C_{100 \%}\right)+\sum\left(W_{0 \%} \cdot T C_{0 \%}\right)} \cdot 100
$$

where: $B C C$ - is the bio-based content of the product expressed as a percentage of the total mass of sample; $W_{100 \%}$ - is the mass of the constituent $100 \%$ bio-based, expressed in grams; $T C_{100 \%}$ - is the total carbon of the constituent $100 \%$ bio-based, expressed as a percentage of the total molar mass of the constituent; $W_{0 \%}$ - is the mass of the constituent $0 \%$ bio-based, expressed in grams; $T C_{0 \%}$ - is the total carbon of the constituent $0 \%$ bio-based, expressed as a percentage of the total molar mass of the constituent. The HuEpC and HuEpA systems contains $55 \mathrm{~g}$ Humins, $40 \mathrm{~g}$ TGPh and $5 \mathrm{~g}$ of BDMA or DMP-30, while the HuEpAC system is composed from $55 \mathrm{~g}$ Humins, $40 \mathrm{~g}$ TGPh, $2.5 \mathrm{~g}$ BDMA and $2.5 \mathrm{~g}$ DMP-30. Following the calculations, the bio-based carbon content for HuEpC resin is $\approx$ $93.14 \%$, for HuEpA resin is $94.12 \%$ and for the HuEpAC resin is $93.63 \%$. 


\section{Conclusions}

In this work, three different thermoset resins were developed by copolymerization of humins with TGPh, a biobased product obtained from algae or bark tree. Following the calculation of the bio-based carbon content of the humins-based resins considering only the carbon content by weight, it was determined that the $B C C$ of the obtained resins is around $94 \%$. The copolymerization's reactivity studies done by DSC reveal a good enthalpy (270-365 $\mathrm{J} . \mathrm{g}^{-1}$ ) reaching the maximum reactivity around the temperature of $106-148^{\circ} \mathrm{C}$ (depending on the formulation). Also, the physico-chemical and mechanical properties of the cured bio-based resins were investigated using different technics as TGA, DMA, Shore hardness test, water absorption and solvents resistance. It was revealed that the obtained materials present very good mechanical properties with values for the $E^{\prime}$ in glassy region $\approx 3.7-$ $5 \mathrm{GPa}$. The tan $\delta$-maxima of the three humins-based resins ranges from $122{ }^{\circ} \mathrm{C}$ to $154{ }^{\circ} \mathrm{C}$. Also, the thermosets hardness values of 82-85 SD confirms the stiffness of these materials. The thermogravimetric analyses of the materials revealed a very good thermal stability with $T_{5 \%} \approx 272-277{ }^{\circ} \mathrm{C}$. The bio-resins developed in this work present also a good chemical resistance over time, the HuEpA resin being unaffected in all solvents tested after 12 days of immersion.

In conclusion, following this study, three humins/epoxy-based copolymers thermosets of $95 \%$ bio-based resins have been successfully developed, with mechanical performance comparable to those of industrial thermoset materials used in construction or automotive sectors.

\section{Acknowledgements}

Funding for this work was received from the European Union's Horizon 2020 Research and Innovation program under Grant Agreement 723268 on a project KaRMA2020.

\section{Conflict of interests}

The authors declare that there is no conflict of interests regarding the publication of this paper.

\section{References}

Arbenz, A., \& Avérous, L. (2015). Chemical modification of tannins to elaborate aromatic biobased macromolecular architectures. Green Chemistry, 17(5), 2626-2646. https://doi.org/10.1039/C5GC00282F

ASTM-D570. (1998). Water Absorption of Plastics.

ASTM-D7028. (2008). Standard Test Method for Glass Transition Temperature (DMA Tg) of Polymer Matrix Composites by Dynamic Mechanical Analysis (DMA).

ASTM-E1640. (2013). Assignment of the Glass Transition Temperature By Dynamic Mechanical Analysis.

Bobade, S. K., Paluvai, N. R., Mohanty, S., \& Nayak, S. K. (2016). Bio-Based Thermosetting Resins for Future Generation: A Review. Polymer - Plastics Technology and Engineering, 55(17), 1863-1896. https://doi.org/10.1080/03602559.2016.1185624

Bouvet, G., Dang, N., Cohendoz, S., Feaugas, X., Mallarino, S., \& Touzain, S. (2015). Impact of polar groups concentration and free volume on water sorption in model epoxy free films and coatings. Progress in Organic Coatings, 96, 32-41. https://doi.org/10.1016/j.porgcoat.2015.12.011

Brostow, W. (2009). Reliability and prediction of long-term performance of polymer-based materials. Pure and Applied Chemistry, 81(3), 417-432. https://doi.org/10.1351/PAC-CON-08-08-03

Brostow, W., \& Hagg Lobland, E. H. (2017). Materials: Introduction and Applications. John Wiley and Sons.

Brostow, W., \& Hagg Lobland, H. E. (2010). Brittleness of materials: Implications for composites and a relation to impact strength. Journal of Materials Science, 45(1), 242-250. https://doi.org/10.1007/s10853-009-39265

Brostow, W., Hagg Lobland, E. H., \& Narkis, M. (2011). The concept of materials brittleness and its applications. Polymer Bulletin, 67(8), 1697-1707. https://doi.org/10.1007/s00289-011-0573-1

Brostow, W., Hagg Lobland, H. E., \& Narkis, M. (2006). Sliding wear, viscoelasticity, and brittleness of polymers. Journal of Materials Research, 21(9), 2422-2428. https://doi.org/10.1557/jmr.2006.0300

Cambridge University Engineering Department. (2003). Materials Data Book. In Cambridge University Engineering Department.

Cantarutti, C., Dinu, R., \& Mija, A. (2019). Biorefinery by-products and epoxy biorenewable monomers: A structural elucidation of humins and triglycidyl ether of phloroglucinol crosslinking. Biomacromolecules. https://doi.org/10.1021/acs.biomac.9b01248 
Chairat, A., Joulia, X., Floquet, P., Vergnes, H., Ablitzer, C., Fiquet, O., \& Brothier, M. (2015). Thermal degradation kinetics of a commercial epoxy resin - Comparative analysis of parameter estimation methods. Journal of Applied Polymer Science, 132(27), 6-9. https://doi.org/10.1002/app.42201

Chen, Y., Xi, Z., \& Zhao, L. (2016). New bio-based polymeric thermosets synthesized by ring-opening polymerization of epoxidized soybean oil with a green curing agent. European Polymer Journal, 84, 435447. https://doi.org/10.1016/j.eurpolymj.2016.08.038

Constant, S., Lancefield, C. S., Weckhuysen, B. M., \& Bruijnincx, P. C. A. (2017). Quantification and Classification of Carbonyls in Industrial Humins and Lignins by 19F NMR. ACS Sustainable Chemistry and Engineering, 5(1), 965-972. https://doi.org/10.1021/acssuschemeng.6b02292

Dinu, R., \& Mija, A. (2019). Cross-linked polyfuran networks with elastomeric behaviour based on humins biorefinery by-products. Green Chemistry, 21, 6277-6289. https://doi.org/10.1039/C9GC01813A

Ebewele, R. (2000). Polymer Science and Technology. In CRC Press. https://doi.org/10.1201/9781420057805

European commission. (2011). Plastic Waste: Ecological and human Health impacts. In Science for Environment Policy.

Fache, M., Viola, A., Auvergne, R., Boutevin, B., \& Caillol, S. (2015). Biobased epoxy thermosets from vanillinderived oligomers. European Polymer Journal, 68, 526-535. https://doi.org/10.1016/j.eurpolymj.2015.03.048

Filiciotto, L., Balu, A. M., Van der Waal, J. C., \& Luque, R. (2018). Catalytic insights into the production of biomass-derived side products methyl levulinate, furfural and humins. Catalysis Today, 302, 2-15. https://doi.org/10.1016/j.cattod.2017.03.008

Flory, P. J. (1953). Principles of Polymer Chemistry. Cornell University Press.

Gao, M., Fu, J., Wang, M., Wang, K., Wang, S., Wang, Z., ..., \& Xu, Q. (2018). A self-template and self activation co-coupling green strategy to synthesize high surface area ternary-doped hollow carbon microspheres for high performance supercapacitors. Journal of Colloid and Interface Science, 524, 165-176. https://doi.org/10.1016/j.jcis.2018.04.027

Geyer, R., Jambeck, J. R., \& Law, K. L. (2017). Production, use, and fate of all plastics ever made. Science Advances, 3(7), 25-29. https://doi.org/10.1126/sciadv.1700782

Hardness Shore D. (n. d.). Retrieved from https://omnexus.specialchem.com/polymerproperties/properties/hardness-shore-d

Hoang, T. M. C., Eck, E. R. H. van, Gardeniers, J. G. E., Lefferts, L., \& Seshan, K. (2015). Humin based byproducts from bioprocessing as potential carbonaceous source for synthesis gas production. Green Chemistry, 17, 959-972. https://doi.org/10.1039/C4GC01324G

Hoang, T. M. C., Lefferts, L., \& Seshan, K. (2013). Valorization of humin-based byproducts from biomass processing - A route to sustainable hydrogen. ChemSusChem, 6(9), 1651-1658. https://doi.org/10.1002/cssc.201300446

Hu, X., Lievens, C., Larcher, A., \& Li, C. Z. (2011). Reaction pathways of glucose during esterification: Effects of reaction parameters on the formation of humin type polymers. Bioresource Technology, 102(21), 1010410113. https://doi.org/10.1016/j.biortech.2011.08.040

Huang, X., Li, W., Li, S., Wang, C., Zhang, M., Sen Luan, ..., \& Wang, Q. (2017). The effect of compressed CO 2 on the self-assembly of surfactants for facile preparation of ordered mesoporous carbon materials. Soft Matter, 13(41), 7505-7513. https://doi.org/10.1039/C7SM01839H

Isikgor, F. H., \& Becer, C. R. (2015). Lignocellulosic biomass: A sustainable platform for the production of biobased chemicals and polymers. Polymer Chemistry, 6(25), 4497-4559. https://doi.org/10.1039/C5PY00263J

Kalogeras, I. M., \& Hagg Lobland, H. E. (2012). The nature of the glassy state: Structure and glass transitions. Journal of Materials Education, 34(3-4), 69-94.

Kang, S., Fu, J., Deng, Z., Jiang, S., Zhong, G., Xu, Y., ..., \& Zhou, J. (2018). Valorization of biomass hydrolysis waste: Activated carbon from humins as exceptional sorbent for wastewater treatment. Sustainability (Switzerland), 10(6), 16-19. https://doi.org/10.3390/su10061795 
Kirke, D. A., Smyth, T. J., Rai, D. K., Kenny, O., \& Stengel, D. B. (2017). The chemical and antioxidant stability of isolated low molecular weight phlorotannins. Food Chemistry, 221, 1104-1112. https://doi.org/10.1016/j.foodchem.2016.11.050

Li, L., Yu, Y., Wu, Q., Zhan, G., \& Li, S. (2009). Effect of chemical structure on the water sorption of aminecured epoxy resins. Corrosion Science, 51(12), 3000-3006. https://doi.org/10.1016/j.corsci.2009.08.029

Li, Y., Fu, X., Duan, D., Liu, X., Xu, J., \& Gao, X. (2017). Extraction and Identification of Phlorotannins from the Brown Alga, Sargassum fusiforme (Harvey) Setchell. Marine Drugs, 15(2). https://doi.org/10.3390/md15020049

Liu, Y., Via, B. K., Pan, Y., Cheng, Q., Guo, H., Auad, M. L., \& Taylor, S. (2017). Preparation and characterization of epoxy resin cross-linked with high wood pyrolysis bio-oil substitution by acetone pretreatment. Polymers, 9(3). https://doi.org/10.3390/polym9030106

Ma, S., Liu, X., Jiang, Y., Tang, Z., Zhang, C., \& Zhu, J. (2013). Bio-based epoxy resin from itaconic acid and its thermosets cured with anhydride and comonomers. Green Chemistry, 15(1), 245-254. https://doi.org/10.1039/C2GC36715G

Menard, K. (2008). Dynamic mechanical analysis - A practical itroduction (2nd ed.). CRC Press Taylor \& Francis Group.

Ménard, R., Negrell, C., Fache, M., Ferry, L., Sonnier, R., \& David, G. (2015). From a bio-based phosphoruscontaining epoxy monomer to fully bio-based flame-retardant thermosets. RSC Advances, 5(87), 7085670867. https://doi.org/10.1039/C5RA12859E

Mija, A. C., Jong, E. De, Waal, J. C. Van Der, \& Klink, G. P. M. Van. (2017). Patent No. WO 2017/074183 A8.

Mija, A. C., Waal, J. C. Van Der, Jong, E. De, \& Klink, G. P. Van. (2018). Patent No. WO2018/062995 A1.

Montané, X., Dinu, R., \& Mija, A. (2019). Synthesis of resins using epoxies and humins as building blocks: A mechanistic study based on in-situ FT-IR and NMR spectroscopies. Molecules, 24(22). https://doi.org/10.3390/molecules24224110

Monti, M., Hoydonckx, H., Stappers, F., \& Camino, G. (2015). Thermal and combustion behavior of furan resin/silica nanocomposites. European Polymer Journal, 67(November), 561-569. https://doi.org/10.1016/j.eurpolymj.2015.02.005

Muralidhara, A., Bado-Nilles, A., Marlair, G., Engelen, V., Len, C., \& Pandard, P. (2018). Humins in the environment: early stage insights on ecotoxicological aspects. Biofuels, Bioproducts and Biorefining, 1-7. https://doi.org/10.1002/bbb.1964

Muralidhara, A., Tosi, P., Mija, A., Sbirrazzuoli, N., Len, C., Engelen, V., .., \& Marlair, G. (2018). Insights on Thermal and Fire Hazards of Humins in Support of Their Sustainable Use in Advanced Biorefineries. ACS $\begin{array}{llll}\text { Sustainable Chemistry and } & \text { 6ngineering, }\end{array}$ https://doi.org/10.1021/acssuschemeng.8b03971

NCS-16785. (2016). Bio-based content certification scheme.

Ng, F., Bonnet, L., David, G., \& Caillol, S. (2017). Novel biobased and food contact epoxy coatings for glass toughening applications. Progress in Organic Coatings, 109(April), 1-8. https://doi.org/10.1016/j.porgcoat.2017.04.008

Norton, G. A., \& Devlin, S. L. (2006). Determining the modern carbon content of biobased products using $\begin{array}{llll}\text { radiocarbon } \quad \text { analysis. } & \text { Bioresource }\end{array}$ https://doi.org/10.1016/j.biortech.2005.08.017

Nouailhas, H., Aouf, C., Le Guerneve, C., Caillol, S., Boutevin, B., \& Fulcrand, H. (2011). Synthesis and properties of biobased epoxy resins. part 1. Glycidylation of flavonoids by epichlorohydrin. Journal of Polymer Science, Part A: Polymer Chemistry, 49(10), 2261-2270. https://doi.org/10.1002/pola.24659

Ornaghi-Junior, H. L., Zattera, A. J., \& Amico, S. C. (2014). Dynamic mechanical properties and correlation with dynamic fragility of Sisal reinforced composites. Polymer Composites, 36(1). https://doi.org/10.1002/pc.22925

Pan, X., Sengupta, P., \& Webster, D. C. (2011). High biobased content epoxy-anhydride thermosets from epoxidized sucrose esters of fatty acids. Biomacromolecules, 12(6), 2416-2428. https://doi.org/10.1021/bm200549c 
Park, C., Cha, H. J., Hong, S. H., Kim, G. Y., Kim, S., Kim, H. S., .., \& Choi, Y. H. (2019). Protective effect of phloroglucinol on oxidative stress-induced DNA damage and apoptosis through activation of the Nrf2/HO-1 signaling pathway in $\mathrm{HaCaT}$ human keratinocytes. Marine Drugs, 17(4), 1-16. https://doi.org/10.3390/md17040225

Patil, S. K. R., \& Lund, C. R. F. (2011). Formation and growth of humins via aldol addition and condensation during acid-catalyzed conversion of 5-hydroxymethylfurfural. Energy and Fuels, 25(10), 4745-4755. https://doi.org/10.1021/ef2010157

Peer, M., Qajar, A., Rajagopalan, R., \& Foley, H. C. (2014). Synthesis of carbon with bimodal porosity by simultaneous polymerization of furfuryl alcohol and phloroglucinol. Microporous and Mesoporous Materials, 196, 235-242. https://doi.org/10.1016/j.micromeso.2014.05.020

Pin, J. M., Guigo, N., Mija, A., Vincent, L., Sbirrazzuoli, N., Van Der Waal, J. C., \& De Jong, E. (2014). Valorization of biorefinery side-stream products: Combination of humins with polyfurfuryl alcohol for composite elaboration. ACS Sustainable Chemistry and Engineering, 2(9), 2182-2190. https://doi.org/10.1021/sc5003769

Ratna, D. (2009). Handbook of Thermoset Resins. Shawbury, Shrewsbury, Shropshire: Smithers Rapra.

Ritchie, H., \& Roser, M. (2018). Plastic Pollution. Retrieved from https://ourworldindata.org/plastic-pollution

Tosi, P., van Klink, G. P. M., Celzard, A., Fierro, V., Vincent, L., de Jong, E., \& Mija, A. (2018). Auto-Crosslinked Rigid Foams Derived from Biorefinery Byproducts. ChemSusChem, 11(16), 2797-2809. https://doi.org/10.1002/cssc.201800778

Tripathi, P. K., Gan, L., Liu, M., Ma, X., Zhao, Y., Zhu, D., ..., \& Rao, N. N. (2014). One-pot assembly of silica@two polymeric shells for synthesis of hollow carbon porous nanospheres: Adsorption of bisphenol A. Materials Letters, 120, 108-110. https://doi.org/10.1016/j.matlet.2014.01.057

Van Zandvoort, I., Wang, Y., Rasrendra, C. B., Van Eck, E. R. H., Bruijnincx, P. C. A., Heeres, H. J., \& Weckhuysen, B. M. (2013). Formation, molecular structure, and morphology of humins in biomass conversion: Influence of feedstock and processing conditions. ChemSusChem, 6(9), 1745-1758. https://doi.org/10.1002/cssc.201300332

Vian, W. D., \& Denton, N. L. (2018). Hardness Comparison of Polymer Specimens Produced with Different Processes. ASEE Annual Conference and Exposition, Conference Proceedings, 2018-June.

Zhou, J. M., \& Lucas, J. P. (1999). Hygrothermal effects of epoxy resin. Part I: the nature of water in epoxy. Polymer, 40(20), 5505-5512. https://doi.org/10.1016/S0032-3861(98)00790-3

Zhu, J., Wu, Y., Zhao, L., Wei, H. L., Chu, H. J., \& He, J. (2011). Study of thermal properties of curing of DGEBA epoxy resin with Hexakis-(4-aminophenoxy)-cyclotriphosphazene. Advanced Materials Research, 284-286, 365-368. https://doi.org/10.4028/www.scientific.net/AMR.284-286.365

\section{Copyrights}

Copyright for this article is retained by the author(s), with first publication rights granted to the journal.

This is an open-access article distributed under the terms and conditions of the Creative Commons Attribution license (http://creativecommons.org/licenses/by/4.0/). 